\title{
Menopausal Stressors as Attributes of Behavioral Changes
}

\author{
FE S. TOLIBAS \\ gvtolibas@yahoo.com \\ Liceo de Cagayan University
}

Date Submitted: May 20, 2007

Final Revision Accepted: September 24, 2007

\begin{abstract}
The study delved into the menopausal stressors as attributes of behavioral changes among the selected tertiary female faculty in Cagayan de Oro City. The researcher used the descriptive design. Forty- four full-time and part-time tertiary instructors in Cagayan de Oro City were chosen as respondents of the study. They experienced either premature, surgical, or normal menopause. The majority of the respondents aged between $56-60$ years old, was married, has doctorates, earned between P10, 000 - P30, 000, and went through the natural type of menopause. The respondents experienced to a low extent the mental, sexual, and physiological (pains) stressors while psychological, social and physiological (discomforts) stressors were experienced to a very low extent. There was a high positive relationship between menopausal stressors and behavioral changes experienced by the menopause women. The women who are in the teaching profession experienced little problem of discomforts brought about by menopausal stressors. The high relationship between menopausal stressors and behavioral changes shows that the higher the menopausal stressors a woman experiences, the higher the degree of behavioral change occurs.
\end{abstract}

Key words - Behavioral Changes, Menopausal stressors, Hormonal Changes 


\section{INTRODUCTION}

Women may find menopause a time to reflect on the past. They may look at their past and present relationships, choices about children, and work satisfaction. Some may experience regrets about certain decisions or unfulfilled dreams. Reflecting on past events and exploring choices made throughout life can prove difficult for some women. While some women feel relieved from regular menstruation, others develop a sense of loss. They see menstruation as a symbol of feminity and womanliness. In silence, they begin to question their female identity. They find it difficult to accept the loss of reproduction, which triggers their feelings of loneliness.

Literally, menopause is a term which means the last menstrual period. It typically occurs in "midlife." It is a normal event in life, characterized by hormonal changes (Dacey \& Travers 2004). It is the beginning of a new phase in a woman's life that will bring different expectations, opportunities, and experiences. The experience of menopause varies widely from woman to woman and from culture to culture. All women undergo the same basic hormonal changes during menopause. A woman's ovaries produce three types of hormones - oestrogen, progesterone, and testosterone. These hormones play a vital role in menstruation, ovulation, and pregnancy.

Some women go through menopause in their thirties. This is called premature menopause. Just as the young girl starts her period early (anytime after nine) and still be normal, she can normally stop menstruating early. Surgical menopause results immediately after the removal of the ovaries. If only one ovary is removed and the remaining one continues to function, then one will go through menopause at the normal time. But when the remaining ovary stops functioning prematurely because of injury to its blood supply during surgery, then premature menopause occurs (Love and Lindsay 1997). Normal menopause takes place when the woman reaches the age of forty-five to fifty years old.

Behavioral changes are evident among women who are in midlife crisis, during or after menopause. Husbands, children, and colleagues can attest to this. While some are old and emotionally exhausted to rear a continuous chain of children, they still move on and even bloom after menopause. However, others feel so weary and disturbed and find themselves unbalanced in given situations that at times they get lost of the many things they ought to do in life. One may breeze through menopause with discomfort or may experience a number of physical and emotional changes.

According to Serrano (2005), changes are likely to happen such as fat accumulation in the body and emergence of facial hair due to the presence of small amounts of the male hormone testosterone. Hot flashes occur in the upper body (the face might look flushed, and red blotches may appear on the chest, neck and arms lasting from 30 seconds to as long as 30 days, one may feel chilled, weak and slightly faint). Sleep disturbances and 
night sweats are followed by chills. One in four midlife women experience insomnia. Lack of sleep may affect one's mood and overall health and ultimately leads to the predictable result of stress and emotional strain (Mansfield 2006).

As a woman goes through menopause, she may experience mood swings, become more irritable or be more prone to emotional upset. An important aspect of relationship between emotion and behavior is the way a person handles menopause. The more stressful the changes take place in the woman's life, the greater the likelihood of illness and psychological stressors to occur such as anxiety, nervousness, tenseness, anger, irritability and depression (Horan 2003). Attitudes are generally regarded to be part of personality. They show wide individual differences which are sometimes linked with actual behavior.

The researcher finds this a mystery from a purely evolutionary point of view. Young and old women have always been curious to find clues to answer few questions such as why women, who almost reach the finishing line of their motherhood or who are in it now, exhibit change of lifestyle, and apparently a sudden shift of behavior that confuses everyone surrounding them. Realizing the uncomfortable truth about this scenario, the researcher endeavors to carry out this study to particularly identify the extent of physiological, mental, psychological, sexual, and social stressors experienced by the tertiary female faculty during and after menopause and to what degree these stressors influenced their behavior in terms of anxiety, assertiveness, dominance, aggression, hostility, social withdrawal, and self-destructive behavior. The result of the sequence of events would somehow affect the behavior of teachers in their dealings with their clientele.

\section{FRAMEWORK}

This study is anchored on the "Life Events Theory of Stress" as cited by Linsky. (1995), which says that as the degree of stressful life events increases, the ability to adopt to the changes decreases. That is, if the stressors brought about by life events - divorce, unemployment, and physical health deterioration due to cessation of the menstrual cycle - the capacity of the individuals to cope diminishes. This is so because the stresses felt by the individual make them difficult to adjust to the changes. Consequently, they develop psychological state of aggression as an adaptive mechanism. Some menopausal women experience mood swings. There is a sudden change of feeling or reaction towards someone or to some given situations. Serious psychological problems, such as depression and emotional distress, are experiences to be considered. In the study of McKinley (2005), women who had a long and symptomatic premenopausal were more likely to feel somewhat distressed. Emotional stressors are considered to be internal to the person who drives the person to behave or feel in certain ways. For instance, if the individual is cheerful then it is assured that her enthusiastic behavior and manner is a reflection of this internal disposition. The facial expression is universally recognized as depicting the emotion of anger, fear, and sadness. 
The stress is felt when hormonal changes occur in the body's equilibrium, upsetting the person. Another stressor which is related to hormones or menstrual cycle is headache. However, this nagging discomfort tends to go away after menopause. Generally, it has to do with blood vessel constriction in the brain. The image of past menopausal women as "drying up" is experienced. It loses sexual lubrication and therefore all interest in sex. The losses of sexual interest and reduced sexual activity or declines in libido are experienced. Women feel released from having to worry about sex. On some occasions, insomnia happens. This is a kind of disturbance of sleep. For instance, when awakened from a good sleep, it will take hours before one falls asleep again. Occasionally, when one fails to follow regular sleeping time, the succeeding nights will be sleepless nights. Hot flashes are very common. One's face gets red and hot because blood rushes to the vessels nearest the surface to release heat more easily and sweats out. These physiological stressors give one the idea of the importance of the physiological systems. The physiological system is important to the maintenance of life. Some theories simply state that a physiological difference results in a given difference in the behavior pattern.

The concept of self-destruction is an act that is self induced. It happens in many forms and for numerous reasons. It can be as simple as not returning an important phone call or as complex as the thoughts that lead to suicide. It is a sequence of events, sometimes even subconsciously performed, but all with the same goal - to destroy some parts or maybe all of one's life. In a lot of cases, self-destruction, self-injury and suicide have very little to do with each other in a technical sense. The only clear-cut similarity is the desire for self-inflicted harm.

A self-destructive person may stay that way for a very long time without ever becoming consciously aware of what he is accomplishing. But, almost all of the people who self injure or become suicidal know what they're doing or end up figuring it out along the way. A large number of self injurers and the majority of those with self-destructive tendencies really have no intention of killing themselves. They actually use the action more as a way to cope or avoid dealing with their life. It's not always the stepping stone to suicide that many people perceive it to be.

In addition, suicidal people do not necessarily exhibit obvious self-destructive behaviors before they attempt to kill themselves. Of course, sometimes the feelings of hopelessness and despair that may lead to self-destruction can elevate to the level of suicidal ideation or attempts. Dropping out of social interactions and normal activities is another sign of potential or worsening mental health problems for an older person. Signs to watch include: having a strong preference for being alone, preoccupation with death themes, withdrawing from family, social, or volunteer activities, and not keeping appointments for medical or personal care.

Depression is a common cause of social withdrawal and is often overlooked in the elderly. It can isolate an individual. Feelings of hopelessness and worthlessness may be overwhelming. Whether mild, moderate, or severe, depression-regardless of age-can always be treated. Geriatric patients are being successfully treated with medications and various forms of psychotherapy. Another frequent-and often treatable-cause of 
social withdrawal among the elderly is failing hearing or vision. Sensory loss can lead to feelings ranging from embarrassment to paranoia. Real strides have been made in the fields of vision and hearing correction. Some seniors feel that an inability to transport themselves or physically keep up with younger family members will make them a burden in participating in social activities. They may imagine they are not really welcome. Sometimes basic changes such as new glasses, a hearing aid, a less strenuous schedule, or reassurances that are wanted will enable the person to partake in and enjoy activities again. Social interactions are an important support toward wellness. They benefit both the older person and the people who care for them.

\section{OBJECTIVES OF THE STUDY}

This study aimed to determine the menopausal stressors as attributes of behavioral changes among the selected tertiary faculty in Cagayan de Oro City. Specifically, it sought to achieve to the following objectives: (1) to describe the profile of menopausal women respondents; (2) to determine the extent the women experienced the menopausal stressors; (3) to assess the degree of behavioral changes; (4) to relate the menopausal stressors to behavioral changes; and (5) to find interventing effects of the women's characteristics on the relationship of the variables.

\section{METHODOLOGY}

The descriptive research design was used to attain the objectives of the study. Fortyfour (44) full-time and part-time tertiary instructors were chosen as respondents of the study. They came from different schools, namely Liceo de Cagayan University, Cagayan de Oro College, Lourdes College, Mindanao Polytechnic State College, and Bukidnon State College. They experienced either premature, surgical, or normal menopause. They were identified by their respective deans.

The instrument used in the study was divided into three parts. Part I drew out the respondents' profile as age, civil status, educational attainment, type of school, family monthly income, and type of menopause. Part II pertained to menopausal stressors. Adopted from Collins (2002), it contained 18 items categorized into five headings: mental, psychological, physiological, sexual, and social. It used the 5-point rating scale - (5) to a very high extent, (4) to a high extent, (3) to a moderate extent, (2) to a low extent, and (1) to a very low extent. Part III pertained to the behavioral changes experienced by the respondents. It used the 4 - point rating scale: (4) always, (3) most of the time, (2) sometimes, (1) rarely, and (0) never.

The components of behavioral changes included anxiety and emotional states, assertive states, dominance, aggression and hostility, social withdrawal, and selfdestructive behavior. This part was adopted from de Jesus (1998). The questionnaire utilized to draw the needed data was tested to determine its validity and reliability. The questionnaire's content was thoroughly reviewed before its distribution for testing. Thirty (30) non-career women of the Couples for Christ Organization in Kauswagan, Cagayan de Oro City were tapped for the study. The index of reliability for Part II was 0.8749, indicating a high degree of reliability. Part III showed a reliability index of 0.85 , indicating 
still a high degree of reliability.

Since the scope of the study was citywide, the researcher distributed the questionnaires through the deans of the colleges and universities. The retrieval of the same was done through mailing, thus the deans were provided with return stamped envelope. The obtained data were processed using the SPSS at the Research and Planning Office of Liceo de Cagayan University. The results were analyzed and interpreted. To describe the characteristics of the variables included in the study, frequency and percentage distribution were used for the respondents' profile, weighted mean for problems two and three, correlation coefficient to determine the relationship between the extent of menopausal stressors and the degree of behavioral changes, and partial correlation to determine the intervening effect of the respondents' profile on the relationship between menopausal stressors and behavioral changes.

\section{RESULTS AND DISCUSSION}

This section discusses the answers to the problems posed in the study, interprets the tests of hypotheses and captures the highlights of the data. The order of discussion follows the sequences of the problems and the hypotheses of the study.

On Profile of Women Respondents

Table 1. Distribution of respondents according to their profile

\begin{tabular}{|c|c|c|}
\hline Variable & Frequency & Percent \\
\hline \multicolumn{3}{|l|}{ Age } \\
\hline $48-50$ & 8 & 18.2 \\
\hline $51-55$ & 12 & 27.3 \\
\hline $56-60$ & 19 & 43.2 \\
\hline \multirow[t]{2}{*}{$61-66$} & 5 & 11.4 \\
\hline & 44 & 100.0 \\
\hline \multicolumn{3}{|l|}{ Civil Status } \\
\hline Single & 7 & 15.9 \\
\hline Married & 28 & 63.6 \\
\hline Widowed & 6 & 13.6 \\
\hline \multirow[t]{2}{*}{ Separated } & 3 & 6.8 \\
\hline & 44 & 100.0 \\
\hline \multicolumn{3}{|l|}{ Educational Attainment } \\
\hline College Graduate & 6 & 13.6 \\
\hline College Graduate with MA Units & 8 & 18.2 \\
\hline M.A./M.S./M.A.T & 8 & 18.2 \\
\hline M.A. with Doctoral Units & 6 & 13.6 \\
\hline \multirow[t]{2}{*}{ Doctoral Degree } & 16 & 36.4 \\
\hline & 44 & 100.0 \\
\hline \multicolumn{3}{|l|}{ Type of School } \\
\hline Public & 18 & 40.9 \\
\hline \multirow[t]{2}{*}{ Private } & 26 & 59.1 \\
\hline & 44 & 100.0 \\
\hline \multicolumn{3}{|l|}{ Family Monthly Income } \\
\hline P 10,000 & 1 & 2.3 \\
\hline P $10,001-$ P 20, 000 & 14 & 31.8 \\
\hline P 20,001-P 30, 000 & 14 & 31.8 \\
\hline P $30,001-$ P 40,000 & 11 & 25.0 \\
\hline $\mathrm{P} 40,001-\mathrm{P} 50,000$ & 3 & 6.8 \\
\hline \multirow[t]{2}{*}{ P 50, 001 above } & 1 & 2.3 \\
\hline & 44 & 100.0 \\
\hline \multicolumn{3}{|l|}{ Type of Menopause } \\
\hline Premature & 3 & 6.8 \\
\hline Artificial & 2 & 4.5 \\
\hline \multirow[t]{2}{*}{ Natural } & 39 & 88.6 \\
\hline & 44 & 100.0 \\
\hline
\end{tabular}


Liceo Journal of Higher Education Research

On Extent of Menopausal Stressors.

Table 2. Extent of the menopausal mental stressors as experienced by tertiary female faculty

\begin{tabular}{|c|c|c|}
\hline Items & Weighted Mean & Verbal Description \\
\hline Difficulty in thinking clearly & 1.67 & Very Low Extent \\
\hline Trouble with remembering things and events & 2.12 & Low Extent \\
\hline Trouble in thinking of the right word/s when speaking or writing & 1.91 & Low Extent \\
\hline Difficulty with diminishing reasoning skills & 1.56 & Very Low Extent \\
\hline Poor in noticing things and identifying objects & 1.70 & Very Low Extent \\
\hline Mean & 1.77 & Low Extent \\
\hline
\end{tabular}

Menopausal mental stressor refers to less retention and recall of facts for a definite period of time, which women experience before or after menopause. The mental stressors were experienced to a low extent as revealed by an overall mean of 1.77 . Rated the highest among the items was trouble with remembering things and events (2.13), while the lowest was difficulty with diminishing reasoning skills (1.56). The mental changes associated with menopause vary from woman to woman. The data show that the respondents experienced mental menopausal stressors to a low extent. It is attributed to the fact that as teachers, they are mentally active as they exercise their academic functions. A number of studies found deterioration in some types of memory. It can be said that as women grow older, they experience memory lapses. An example is a lapse on prospective memory, a memory required to carry out planned actions at the appropriate time, such as meeting a friend for lunch, taking a medication or recalling facts and information that have been stored in the long-term memory. It is a fact that the memory declines with age (Bradberry 2005). Furthermore, Whiting and Smith found out that middle adults have more difficulty than younger adults in memory tasks requiring more cognitive effort such as recall.

Table 3. Extent of the menopausal psychological stressors experienced by tertiary female faculty

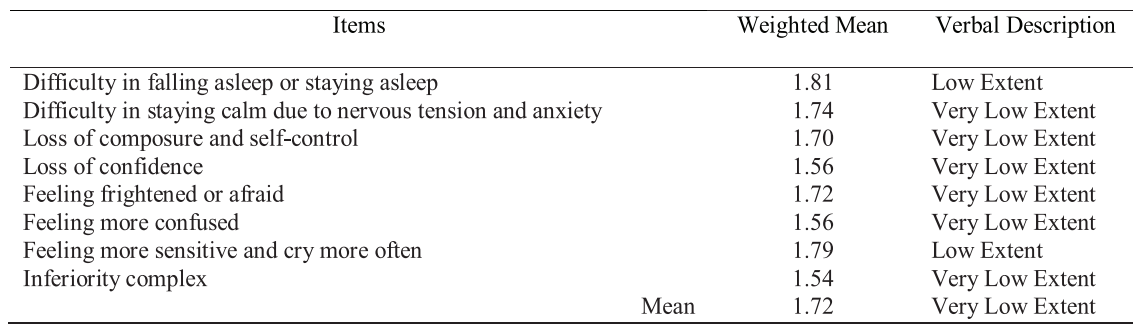

The psychological stressors are associated with the possibilities for human contact and interaction. Overall, the psychological stressors were experienced to a very low extent. Sleep problems may arise and include the viability and a generally unsatisfying sleep period, which is usually indicated by feeling tired after what seemed the proper amount of sleep (Papalia \& Feldman 2004). Inferiority complex was rated the lowest. While other psychological factors, like loss of confidence, fear, confusion, and sensitivity are felt, their self-esteem remained the same. In other words, they remain productive, composed, and able to exercise their authority to perform the various activities called for their profession. The problem on difficulty in falling asleep is attributed to some factors which are unrelated 
to menopause such as drinking caffeinated beverage or lifestyle modifications constrained by excessive work - related activities or social commitments.

Table 4. Extent of the menopausal psychological stressors experienced by tertiary female faculty

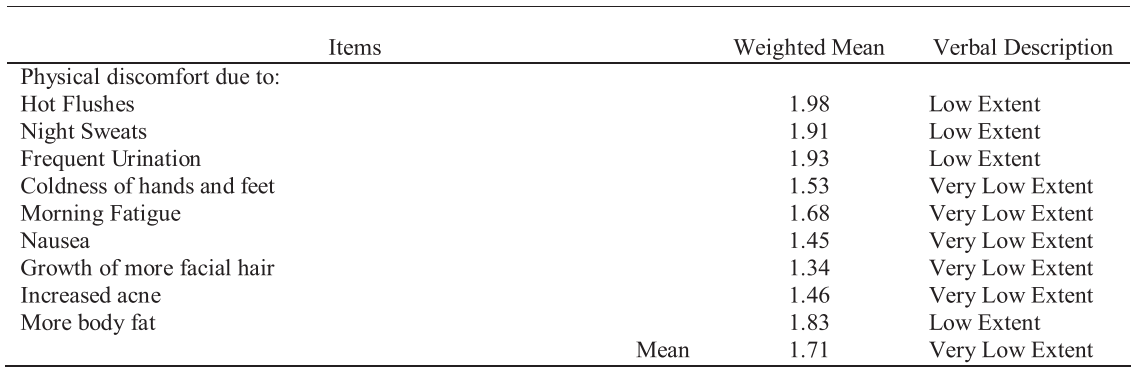

The physiological stressors refer to the properties in the brain, nervous system, muscles, and bones which make the movement and behavior possible with physical discomfort (Love 1997). Table 5 shows the physical discomforts were experienced to a low extent by the respondents included hot flushes (1.98), frequent urination (1.93), night sweats (1.91), and more body fat (1.83). The rest of the physical discomforts, such as coldness of hands and feet, morning fatigue, nausea, and increased acne were experienced to a very low extent.

Table 5. Extent of the menopausal physiological stressors experienced by tertiary female faculty

\begin{tabular}{lcc}
\hline & Weighted Mean & Verbal Description \\
Body pains/illnesses: & & Very Low Extent \\
\hline Allergies & 1.71 & Very Low Extent \\
Asthma & 1.45 & Very Low Extent \\
Anemia & 1.46 & Low Extent \\
Headache & 1.76 & Low Extent \\
Lower back pain & 1.92 & Low Extent \\
Muscle and joint pains & 2.07 & Very Low Extent \\
Coronary disease/heart ailment & 1.66 & Low Extent \\
Increased blood pressure & 1.84 & Low Extent \\
Rise in blood sugar & 1.92 & Low Extent \\
Loss of firmness and fullness of the skin & 1.79 & Low Extent \\
Shrinking and sagging of the breast & 1.88 & Very Low Extent \\
Thinning of the pubic hair & 1.73 & Low Extent \\
\end{tabular}

The pains and illnesses experienced to a low extent by the respondents included headache (1.76), lower back pain (1.92), muscle and joint pains (2.07), increased blood pressure (1.84), rise in blood sugar (1.84), loss firmness and fullness of the skin (1.79), and shrinking and sagging of breast (1.88). The rest of body pains and illnesses, such as allergies (1.71), asthma (1.45), anemia (1.46), coronary disease/heart ailment (1.66), and thinning of the pubic hair (1.73), were experienced to a very low extent. As women reach the age of $40 \mathrm{~s}$ and 50s, they undergo changes due to the decline of estrogen. They experience the ceasing of their ovaries' normal function, which leads to a lot of physiological changes. The onset of menopause usually lowers the level of hormones in the blood, which effects include hot flushes, night sweat, anxiety attacks, mood swings and even depression, not to mention the rise of blood sugar and lower back pain. All these come for one reason 
Liceo Journal of Higher Education Research

- hormone imbalance (Linsky 1995). Menopause, nevertheless, is a psychological as well as a physical milestone in the ageing process, and such milestone may produce varying degrees of stress (Arsendatama 2005).

Table 6. Extent of the Menopausal Sexual Stressors Experienced by Tertiary Female Faculty

\begin{tabular}{lccl}
\hline & Items & Weighted Mean & Verbal Description \\
\hline Less receptiveness to sex & 1.76 & Low Extent \\
Diminished sex drive & 1.70 & Very Low Extent \\
Less sexual fantasies & 1.83 & Low Extent \\
Vaginal dryness & 1.95 & Low Extent \\
Vaginal itching and pain & & 1.51 & Very Low Extent \\
& Mean & 1.80 & Low Extent \\
\hline
\end{tabular}

The sexual stressors refer to the lessening sexual desire and fantasies caused by vaginal discomfort due to dryness, thus making sexual activity painful and less pleasurable. The data in Table 6 reveal that vaginal dryness (1.95), less sexual fantasies (1.83), and less receptiveness to sex (1.76) were experienced to a low extent. On the other hand, diminished sex drive (1.70) and vaginal itching and pain (1.51) were experienced to a very low extent. The period before menopause is known as the premenopausal when some loss of libido occurs. The hormone called progesterone is responsible for this downfall and is the main cause of hormonal imbalance. The job of hormones is to regulate certain processes in the body. An insufficiency in hormones disrupts this balance and creates problems. Vaginal dryness and discomfort can force women to avoid having sex altogether (Calhoun 2000).

Estrogen is the primary sex hormone in a woman. The loss of estrogen leads to a loss of sexual desire. Women produce testosterone in low levels. Testosterone is also responsible for promoting sexual drive. The once supple tissues of the vagina that produce lubrication become thin and dry in the absence of estrogen, which normally sends messages to the genitals to prepare for sexual activity (Beckham 1995).

Table 7. Extent of the menopausal social stressors as experienced by tertiary female faculty

\begin{tabular}{|c|c|c|c|}
\hline Items & & Weighted Mean & Verbal Description \\
\hline Loss of interest in family socialization & & 1.52 & Very Low Extent \\
\hline Loss of interest in meeting acquaintances & & 1.57 & Very Low Extent \\
\hline Loss of competitive edge & & 1.64 & Very Low Extent \\
\hline Loss of energy in associating with people & & 1.64 & Very Low Extent \\
\hline Less assertivism & & 1.54 & Very Low Extent \\
\hline \multirow[t]{2}{*}{ Less motivation } & & 1.63 & Very Low Extent \\
\hline & Mean & 1.57 & Very Low Extent \\
\hline
\end{tabular}

The social stressors refer to the loss of enthusiasm to associate with other people, less interest in joining family reunions and meeting new acquaintances. In other words, menopausal women prefer to live a quiet life (Table 7). They do not exert effort to assert for they have lost self-motivation and confidence. The data show that loss of competitive edge (1.64), loss of energy in associating with people (1.64), less motivation (1.63), loss in meeting acquaintances (1.57), less assertiveness (1.54), and loss of interest in family socialization (1.52) were all experienced to a very low extent. They are less motivated, assertive, and competitive because of the realization that life is halfway over. It involves 
reflection on what they have done with their lives often with feelings that they can no longer accomplished beyond the expectations of people surrounding them, hence the feeling of insecurity becomes evident. However, the respondents rated this category to a very low extent (1.57).

On Behavioral Changes

Table 8. Degree of behavioral change of the respondents in terms of anxiety and emotional states

\begin{tabular}{|c|c|c|}
\hline Items & $\begin{array}{l}\text { Weighted } \\
\text { Mean }\end{array}$ & Interpretation \\
\hline Feeling of tension/confused and disconnected thought process & 1.57 & Very Low \\
\hline Worry and emotional fear & 1.77 & Low \\
\hline Apprehension and uncertainty & 1.64 & Very Low \\
\hline Restlessness and unstable emotion & 1.60 & Very Low \\
\hline Feeling of unexplained unhappiness & 1.74 & Very Low \\
\hline Persistent anger if a goal/activity is not achieved & 1.76 & Low \\
\hline Persistent irritability and change of mood & 1.83 & Low \\
\hline Explosive outburst & 1.60 & Very Low \\
\hline Heightened emotional tone & 1.78 & Low \\
\hline Agitated feelings & 1.78 & Low \\
\hline Mean & 1.74 & Very Low \\
\hline
\end{tabular}

Table 8 shows that the overall degree of behavioral changes experienced by the respondents was very low (1.74). Specifically, experienced at a low degree were worry and emotional fear (1.77), persistent anger if a goal/activity is not achieved (1.76), persistent irritability and change of mood (1.83), heightened emotional tone (1.78), and agitated feelings (1.78). Experienced at a very low degree were feeling of tension/confused and disconnected thought process (1.57), apprehension and uncertainty (1.64), restlessness and unstable emotion (1.60), feeling of unexplained unhappiness (1.74), and explosive outburst (1.60).

The data indicate that when menopause hits, women go through anxiety and depression. Anxiety for most of them is an inevitable part of life. Menopausal women encounter everyday real life situations such as meeting deadlines on the submission of reports, payment of bills, rearing children, and other financial obligations to settle. Occasionally, the real life issues that elicit deeper emotional concerns include fear of abandonment, rejection, or not being loved (Clay 2005). Though these are experienced to a very low extent, they can interfere women's quality of life and their ability to function optimally in their daily routine.

Table 9. Degree of behavioral change of the respondents in terms of assertive states

\begin{tabular}{|c|c|c|c|}
\hline Items & & Weighted Mean & Interpretation \\
\hline Assert position without listening to others & & 1.65 & Very Low Extent \\
\hline Like to be independent of others in deciding things & & 2.07 & Low Extent \\
\hline Increased reactivity & & 1.83 & Low Extent \\
\hline Challenge others who are in a position of authority & & 1.60 & Very Low Extent \\
\hline Become confident in dealing with adversity & & 2.39 & Low Extent \\
\hline \multirow[t]{2}{*}{ Do things better than other people can } & & 2.41 & Low Extent \\
\hline & Mean & 1.99 & Low Extent \\
\hline
\end{tabular}

The data in Table 9 reveal that the respondents have learned to immerse in the culture of the institutions they belong. The low degree of assertiveness indicates that the 
respondents are clear about what they feel, what they need, and how they can achieve their targets. They are able to communicate calmly without attacking other people. They know their boundaries, feel comfortable to defend their positions even if they provoke conflict, feel confident in handling issues if they occur, able to talk openly about themselves, and able to listen to others with appropriateness and flexibility (Salovey 2000). Overall, they are confident as they function in social institutions.

Table 10. Degree of behavioral change of the respondents in terms of dominance

\begin{tabular}{|c|c|c|}
\hline Items & $\begin{array}{l}\text { Weighted } \\
\text { Mean }\end{array}$ & Interpretation \\
\hline Like to be the center of attention in a group & 1.38 & Very Low Extent \\
\hline Feeling of superiority complex & 1.53 & Very Low Extent \\
\hline Desire to be recognized at all times & 1.50 & Very Low Extent \\
\hline Like to ask questions which no one will be able to answer & 1.38 & Very Low Extent \\
\hline Too proud to have done a difficult job well & 1.68 & Very Low Extent \\
\hline $\begin{array}{l}\text { Desire to excel in solving problems that other people have difficulty } \\
\text { with }\end{array}$ & 1.95 & Low Extent \\
\hline Persistent desire to direct the actions of other people & 1.78 & Low Extent \\
\hline 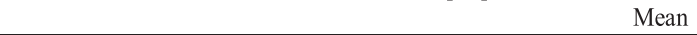 & 1.60 & Very Low Extent \\
\hline
\end{tabular}

In terms of dominance (Table 10), the respondents experienced to a low extent the desire to excel in solving problems that other people have difficulty with (1.95) and the persistent desire to direct the action of other people (1.78). The rest of the items, such as like to be the center of attention in a group (1.38), feeling of superiority complex (1.53), desire to be recognized at all times (1.50), like to ask questions which no one will be able to answer (1.38), and too proud to have done a difficult job well (1.68), were rated to a very low extent. Menopausal women tend to be dominant due to the decline of hormones and other related hereditary factors (Birren \& Schiae 1997). Since the respondents are mostly educated, they feel that their experience in life clothed them with the authority to direct the actions of other people and feel proud to have accomplished well a job and eventually expect due recognition. However, as the findings indicate, they allow others to play their role in life, indicating that they still recognize their peers, colleagues, family, and other members of the society.

Table 11. Degree of behavioral change of the respondents in terms of aggression and hostility

\begin{tabular}{|c|c|c|}
\hline Items & Weighted Mean & Interpretation \\
\hline Physical violence directed at others & 1.24 & Very Low Extent \\
\hline Intrafamily assault & 1.26 & Very Low Extent \\
\hline Criticize others publicly & 1.33 & Very Low Extent \\
\hline Blame others when they go wrong & 1.49 & Very Low Extent \\
\hline Quarrel others who argue and who show contradictory ideas & 1.33 & Very Low Extent \\
\hline Mean & 1.37 & Very Low Extent \\
\hline
\end{tabular}

On the behavioral change of the respondents in terms of aggression and hostility, physical violence directed at others (1.24), intrafamily assault (1.26), criticizing others publicly (1.33), and blaming others when they go wrong (1.49) were all rated to a very low extent (Table 11). It is a reaction to circumstances in which essential requirements of our nature remain unfulfilled, which may lead to quarrel as a result of arguments due to differences in ideas, and, when not settled appropriately, may eventually end up in 
physical violence. The respondents rated these variables to a very low extent because they are teachers and are considered role models in the community. They respect personal boundaries of others and are aware of the liabilities should they harm others. Extra care must be exercised in their behavior as this is linked to self-esteem. They tend not to cause stress on others and experience decreased levels of stress on themselves to avoid relational conflict that may hinder the realization of some personal goals. This involves expressing their own needs while respecting the rights of others. Maintaining the dignity of both parties will undoubtedly develop healthier and more satisfying relationship (Olsen 2006).

Table 12. Degree of behavioral change of the respondents in terms of social withdrawal

\begin{tabular}{|c|c|c|c|}
\hline Items & & $\begin{array}{c}\text { Weighted } \\
\text { Mean }\end{array}$ & Interpretation \\
\hline Feel timid in the presence of other people & & 1.67 & Very Low Extent \\
\hline Avoid responsibilities and obligations & & 1.50 & Very Low Extent \\
\hline Desire towards exclusiveness and isolation & & 1.67 & Very Low Extent \\
\hline Neglect of personal grooming & & 1.30 & Very Low Extent \\
\hline Loss of spontaneous desire to interact with others & & 1.55 & Very Low Extent \\
\hline Unfriendly attitude towards others & & 1.25 & Very Low Extent \\
\hline & Mean & 1.50 & Very Low Extent \\
\hline
\end{tabular}

As to the degree of behavioral change in terms of social withdrawal, Table 12 shows the respondents rated to a very low extent feeling timid in the presence of other people (1.67), avoiding responsibilities and obligations (1.50), desiring towards exclusiveness and isolation (1.67), neglecting of personal grooming (1.30), loss of spontaneous desire to interact with others (1.55), and unfriendly attitude towards others (1.25). The data suggest that women go through changes in their behavior during pre - and post - menopausal stages.

The stereotypes of a woman - sociable, interactive, friendly, daring, and concern for beauty tips - start to diminish. They are startled by the change in their feelings towards social responsibilities. They prefer to be in what we call "quiet nest;" nevertheless, they are still involved in school activities to keep themselves preoccupied in order to make their midlife years still productive and enjoyable. They are on the edge of a major life reassessment that makes them better persons and helps them keep a good relationship with the people around them (Papalia 2006).

Table 13. Degree of behavioral change of the respondents in terms of self-destructive behavior

\begin{tabular}{lccc}
\hline & Items & Weighted & Interpretation \\
& Mean & \\
\hline Alcoholism & 1.14 & Very Low Extent \\
Drug Use & 1.12 & Very Low Extent \\
Smoking & 1.12 & Very Low Extent \\
Attempted Suicide & 1.12 & Very Low Extent \\
Deviant Behavior & 1.14 & Very Low Extent \\
& & 1.13 & Very Low Extent \\
\hline
\end{tabular}


Table 13 shows the respondents' degree of self-destructive behaviors. Deviant behavior (1.14), drug use (1.12), smoking (1.12), and attempted suicide (1.12) were experienced to a very low extent. The data imply that the respondents are very much aware of the health effects alcoholism, drug use, and smoking. They consider selfdestructive behaviors as unhealthy patterns of responding to feelings of insecurities. It is important for them not to entertain any form of self-destructive behavior, instead apply their skills to bring about fruitful and meaningful learning experiences and continue to move around with self-assurance, confidence, and self-determination. They instill in their minds that the use of drugs, in an attempt to control emotions, would bring harmful physical effects. Smoking, alcoholism, and the display of deviant behavior are recognized as self-destructive, thus least resorted to (Mill 2004).

Table 14. Test of relationship between the extent of menopausal stressors and the degree of behavioral changes

\begin{tabular}{|c|c|c|c|c|c|c|c|c|c|c|c|c|c|c|c|c|c|c|c|c|}
\hline \multirow{3}{*}{$\begin{array}{l}\text { Behavioral } \\
\text { Changes }\end{array}$} & \multicolumn{20}{|c|}{ Extent of menopausal stressors } \\
\hline & \multicolumn{4}{|c|}{ Mental } & \multicolumn{3}{|c|}{ Psychological } & \multicolumn{5}{|c|}{ Physiological } & \multicolumn{4}{|c|}{ Sexual } & \multicolumn{4}{|c|}{ Social } \\
\hline & Corr & Prob & Rel & Ho: & Corr & Prob & Rel & $\begin{array}{l}\text { H } \\
\text { o: }\end{array}$ & Corr & Prob & $\begin{array}{l}\mathrm{R} \\
\mathrm{el}\end{array}$ & $\begin{array}{l}\text { H } \\
\text { o: }\end{array}$ & Corr & Prob & $\begin{array}{l}\mathrm{R} \\
\mathrm{el}\end{array}$ & $\begin{array}{l}\text { H } \\
\text { o: }\end{array}$ & Corr & $\begin{array}{c}\text { Pro } \\
\text { b }\end{array}$ & Rel & Ho: \\
\hline $\begin{array}{l}\text { Anxiety and } \\
\text { Emotional } \\
\text { States }\end{array}$ & 1.0 & .000 & VH & $\mathbf{R}$ & .67 & .024 & $\mathbf{M}$ & $\mathbf{R}$ & .77 & .005 & $\mathbf{H}$ & $\mathbf{R}$ & .67 & .023 & $\mathbf{M}$ & $\mathbf{R}$ & .79 & .004 & $\mathbf{H}$ & $\mathbf{R}$ \\
\hline Assertiveness & .67 & .024 & $\mathbf{M}$ & $\mathbf{R}$ & 1.0 & .000 & VH & $\mathbf{R}$ & .69 & .017 & $\mathbf{M}$ & $\mathbf{R}$ & .62 & .040 & $\mathbf{M}$ & $\mathbf{R}$ & .54 & .081 & $\mathbf{M}$ & NR \\
\hline Dominance & .59 & .052 & $\mathbf{M}$ & $\mathbf{R}$ & .67 & .024 & $\mathbf{M}$ & $\mathbf{R}$ & .87 & .000 & $\mathbf{H}$ & $\mathbf{R}$ & .79 & .004 & $\mathbf{H}$ & $\mathbf{R}$ & .77 & .005 & $\mathbf{H}$ & $\mathbf{R}$ \\
\hline $\begin{array}{l}\text { Aggression } \\
\text { and Hostility }\end{array}$ & .77 & .005 & $\mathbf{H}$ & $\mathbf{R}$ & .69 & .017 & $\mathbf{M}$ & $\mathbf{R}$ & 1.0 & .000 & $\begin{array}{l}\mathrm{V} \\
\mathrm{H}\end{array}$ & $\mathbf{R}$ & .89 & .000 & $\mathbf{H}$ & $\mathbf{R}$ & .89 & .000 & $\mathbf{H}$ & $\mathbf{R}$ \\
\hline $\begin{array}{l}\text { Social } \\
\text { Withdrawal }\end{array}$ & .67 & .023 & $\mathbf{M}$ & $\mathbf{R}$ & .62 & .040 & $\mathbf{M}$ & $\mathbf{R}$ & .89 & .000 & $\mathbf{H}$ & $\mathbf{R}$ & 1.0 & .000 & $\begin{array}{l}\mathrm{V} \\
\mathrm{H}\end{array}$ & $\mathbf{R}$ & .92 & .000 & VH & $\mathbf{R}$ \\
\hline $\begin{array}{l}\text { Self- } \\
\text { Destructive } \\
\text { Behavior }\end{array}$ & .79 & .044 & $\mathbf{H}$ & $\mathbf{R}$ & .54 & .081 & $\mathbf{M}$ & $\mathbf{R}$ & .89 & .000 & $\mathbf{H}$ & $\mathbf{R}$ & .92 & .000 & $\begin{array}{l}\mathrm{V} \\
\mathrm{H}\end{array}$ & $\mathbf{R}$ & 1.0 & .000 & VH & $\mathbf{R}$ \\
\hline $\begin{array}{l}\text { Overall } \\
\text { Correlation }\end{array}$ & & .752 & $\mathbf{H}$ & $\mathbf{R}$ & & .702 & $\mathbf{H}$ & $\mathbf{R}$ & & .856 & $\mathbf{H}$ & $\mathbf{R}$ & .81 & .000 & $\mathbf{H}$ & $\mathbf{R}$ & & .822 & $\mathbf{H}$ & $\mathbf{R}$ \\
\hline
\end{tabular}

Table 14 presents the correlation coefficients on the test of relationship between the extent of menopausal stressors and the degree of behavioral changes among the selected tertiary female faculty in Cagayan de Oro City. The relationship between mental stressors and behavioral changes was high as disclosed by the correlation coefficient of .75. Hence, the null hypothesis was rejected in this case. Specifically, a very high positive relationship was established between mental stressor and anxiety and emotional states and a high positive relationship between mental stressor and aggression and hostility ( $r=.77)$ and self-destructive behavior ( $\mathrm{r}=.79$ ). These findings indicate that the higher the mental stress a woman experiences, the higher the degree of behavioral change occurs. As postulated by Freud (cited by Hall 1998), anxiety, aggressive state of behavior, and physical hostility 
and violence are consequences of mental conflict when an individual is confronted with inevitable repression brought about by certain twarted impulses and drives. In this study, the twarted impulses and drives created a negative mental state of mind as women experienced uncomfortable menopausal syndrome. In the menopausal stage, women who cannot meet appropriate mental adjustment usually experience unrealistic fears, irrational emotional states, feeling of isolation and hostile behavior patterns.

The data further reveal that a moderate positive relationship existed between mental stressors and behavioral changes in terms of assertiveness ( $\mathrm{r}=.67)$, dominance $(\mathrm{r}=.59)$, and social withdrawal ( $\mathrm{r}=.67)$. These significant relationships indicate that behavioral changes occur when mental stress occurs. Coping with this situation, women exert effort to maintain some degree of control over their significant others by being assertive and dominant. The development of superiority complex is a denial of the lost of self-esteem during the menopausal stage. The feeling of resentment as well as concern about being treated as of no importance may result in being dominant. In addition, some may tend to develop a trait of introversion and prefer being isolated from the society and even from their families. Birren and Schaie (1997) supported the positive relationship between mental stress during menopausal stage and behavioral changes when they posited that mental stress lessens the menopausal women's self-esteem and increases their self-doubts. These, in turn, result in negative coping mechanisms such as exercising control over others or, in the contrary, withdrawing from others and feeling a sense of contentment of being alone.

Moreover, a significant high positive relationship was found between psychological stress and behavioral changes as disclosed by the overall correlation coefficient of .70. Thus, the null hypothesis was rejected in this case. Specifically, a perfect positive relationship was established between psychological stress and assertiveness $(r=1.0)$. A moderate positive relationship existed between psychological stress and other behavioral changes in terms of anxiety and emotional states $(r=.67)$, dominance $(r=.67)$, aggression and hostility $(\mathrm{r}=.69)$, social withdrawal $(\mathrm{r}=.62)$, and self-destructive behavior $(\mathrm{r}=54)$. The findings imply that women become assertive when they experience psychological stress caused by menopausal discomforts. Assertiveness is a denial sign of aging (Mc Connell 1996).

Furthermore, a significant moderate relationship existed between psychological stress and behavioral changes in terms of decreased participation of menopausal women in the external social environment, hypersensitivity, sleep disturbance, and mental depression. The psychological stress may have caused these women to think uncritically, even shout irrationally, and feel hostile to others. The findings find support in the statement of Lazarus (1996) that psychological stress among aging menopausal women has been linked to a variety of aggression, anxiety, irrational defense mechanisms, irritability, impulsive behavior, irrational vices, unbecoming acts, and personal disintegration.

The data further disclose that a positive relationship existed between physiological stress and behavioral changes as revealed by the overall correlation coefficient of 85 . In particular, a very high positive relationship was observed between physiological 
stress and aggression and hostility ( $\mathrm{r}=1.0)$. A high positive relationship existed between psychological stress and the other indicators of behavioral changes such as anxiety and emotional states $(\mathrm{r}=.77)$, dominance $(\mathrm{r}=.87)$, social withdrawal $(\mathrm{r}=.89)$, and self-destructive behavior $(\mathrm{r}=.89)$. A moderate positive relationship was established between physiological stress and assertiveness ( $\mathrm{r}=.69)$.

Hence, the null hypothesis was rejected in this case. The data indicate that the uncomfortable physical changes brought about by menopause cause behavioral changes. These changes included moody temperament, violent reactions, anxiety, and indulgence in some uncalled for vices which are perceived as coping mechanisms against physiological stressors.

The positive relationship between physiological stress and behavioral changes finds support in the Theory of General Adaptation Syndrome formulated by Dohrenwend (1998). Moreover, a high positive relationship existed between sexual stress and behavioral changes as revealed by the overall correlation coefficient of .81 . Hence, the null hypothesis was rejected in this case. The findings indicate that the higher the sexual frustration occurs, the more women experience anxiety and emotional states, assertiveness, dominance, aggression and hostility, social withdrawal, and self-destructive behavior. Women who experience cessation of the menstrual cycle feel a decline in sex drive that leads to real physical incapacity and gynecological discomfort. This type of frustration often leads to depression over the loss of ability in the sexual function. These women may become moody and feel less in control of themselves. The woman's hormonal cycle ceases at the onset of menopause and sexual receptivity and sexual attractiveness diminish. Coelho (1998) stated that women become temperamental, violent, and manifest control over other things when the sexual drive is thwarted.

Furthermore, the relationship between social stress and behavioral changes was established to be highly positive as disclosed by the overall correlation coefficient of .82 . The findings indicate that as social stress increases, the behavioral changes also increase. The effect of social stresses on the respondents' behavior could be attributed to the sense of meaninglessness that the menopausal women feel which decreases their interest in associating with people (Larson and David, 2004).

Table 15. Partial correlation on the intervening effect of the respondents' profile on the relationship between menopausal stressors and behavioral changes

\begin{tabular}{lcccccc}
\hline \multicolumn{1}{c}{ Variables } & Partial $\mathrm{r}^{2}$ & $\begin{array}{c}\text { Beta } \\
\text { Coefficient }\end{array}$ & F Value & Probability & $\begin{array}{c}\text { Interpretation } \\
\text { Decision on } \\
\text { Ho: }\end{array}$ \\
\hline $\begin{array}{l}\text { Type of } \\
\text { Menopausal }\end{array}$ & .216447 & .276527 & .359 & .5811 & Not Significant & Accepted \\
Age & -.231756 & -.408596 & .412 & .5558 & Not Significant & Accepted \\
$\begin{array}{l}\text { Civil Status } \\
\text { Type of School }\end{array}$ & -.260977 & -.487564 & 1.439 & .2966 & Not Significant Accepted \\
$\begin{array}{l}\text { Family Monthly } \\
\text { Income }\end{array}$ & .070017 & -.812730 & 1.224 & .3307 & Not Significant & Accepted \\
$\begin{array}{l}\text { Educational } \\
\text { Attainment }\end{array}$ & .453219 & 1.298036 & 2.096 & .2212 & Not Significant & Accepted \\
\hline
\end{tabular}


Table 15 presents the partial correlation analysis on the intervening effect of the respondents' personal profile on the relationship between menopausal stressors and behavioral changes. The data disclose that the respondents' profile did not have significant intervening effect on the relationship between menopausal stressors and behavioral changes. The findings imply that the interplay between the menopausal stressors and behavioral changes is not affected by the women's age, civil status, type of school, family monthly income, educational attainment, and type of menopause.

\section{CONCLUSIONS}

Women who are in the teaching profession experience little problem of discomforts brought about by menopausal stressors. This is attributed to their constant interaction in the academe and in the community, thus the identified stressors are less felt and well handled.

The manifestation of anxiety, dominance, aggression/hostility, social withdrawal and self-destructive behavior is also to a very low extent among educators. As role models, they, under any circumstances, have to restrain their behavior to gain the respect of people around them.

The high relationship between menopausal stressors and behavioral changes shows that the higher the menopausal stressors a woman experiences, the higher the degree of behavioral change occurs. Therefore, a menopause woman exerts much effort to maintain some degree of control over her behavior. She takes confidence of the knowledge that this experience is simply part of aging and happens to every woman regardless of age, civil status, educational attainment, and income. It is important for her to know how to cope with particular changes in her life. One of the coping mechanisms is the language of normality that allows her to basically accept the reality with open arms and to go through it gracefully.

\section{LITERATURE CITED}

Arsendatama, R. (2005). Menopause and anxiety: how to bring natural relief. Retrieved from: http://www.article country.com/category 188.htm.

Beckham, N. (1995). Natural therapies for menopause. Penguin books, Australia Lld.

Birren, J.E. \& Schaie, R.W. (1997). Handbook of the psychology of aging. New York: Van Nostrand Leinhold Inc.

Bradberry, T. (2005). The emotional intelligence. Quick Book USA Copy Wright Simon and Schuster.

Calhoun, J. F. (2000). Psychology of adjustments. 3rd edition. Mc Graw Hill 1221 Ave-New York.

Clay, R. A. (2005). Replace midlife myths with facts. Retrieved from: http://www. apa.org/monitor/apro3/researchers.htmlResearch. 
Liceo Journal of Higher Education Research

Coelho, G.V. (1998). Coping and adaptation. New York: Basic Books.

Dacey, J. \& Travers, J. (2004). Human development across the life plan. Mc Graw Hill Company.

Dubrin, A. J. (2005). Fundamentals of organizational behavior. South-Western of Thomson Corp.

Hall. L. C. (1998). Theories of personality New York: Solomon Guggenheim foundation, Horan, L. (2003) Hormones and menopause. Retrieved from: http://www. myctm.org/articles/LH-hormonesandmenopause.php.

Larson, R. \& David, B. (2002). Personality psychology. Mc Graw-Hill Inc. Avenue of the American, New York.

Lazarus, R.S. (1996). Psychological stress and the coping stress. New York: Mc Graw-Hill.

Linsky, A.S. (1995). Stress, culture and aggression. London: Yale Publicity.

Love, S. (1997). Dr. Susan Love's hormones book. Random House Inc., New York, USA.

Mansfield, D. (2006). Educational resources: sleep disturbance during the menopause. Retrieved from: http://www.menopause.org.au/public/professional development low libido.asp.

Mc Connell, J. (1996). Understanding human behavior. 5th edition. CBS College Publishing.

Mc Kinley, F. (2005) Menopause and Anxiety How To Bring Natural Relief. Retrieved from: http://www.content-syndication.org/health/diseases.htm.

Mill, D. J. (2004). About menopause ending confusion about menopause symptoms and treatment. Retrieved from: http://www.womentowomen.com/menopause/ endingconfusion.asp.

Olsen, D. (2006) Signs and symptoms of menopause. Retrieved from: http://www. menopause atoz.com/00086.

Papalia, D. (2004). Human development. 9th Edition. Mc Graw-Hill Co., Inc., 1221 Avenue of the American, New York, New York.

Papalia, D. \& Feldman O. (2004). Human development. 9th Edition. Mc Graw-Hill 1221 Avenue of the American, New York.

Salovey, R. (2000). Emotional state and physical health. American Psychologist.

Serrano, J. (2005). Biological and social constructions of menopause. Retrieved from: http://www.phssa.org/pubs/nchssl/biological and social.htm. 